\title{
Geographic Barriers Drive Disparities in Specialty Center Access for Older Adults with Huntington's Disease
}

\author{
Thanh Phuong Pham Nguyen ${ }^{\mathrm{a}, \mathrm{b}, \mathrm{c}, \mathrm{d}, *}$, Licia Bravo $^{\mathrm{g}, \mathrm{h}}$, Pedro Gonzalez-Alegre $\mathrm{c}, \mathrm{f}$ \\ and Allison W. Willis ${ }^{\mathrm{a}, \mathrm{b}, \mathrm{c}, \mathrm{d}, \mathrm{e}}$ \\ ${ }^{a}$ Center for Pharmacoepidemiology Research and Training, Center for Clinical Epidemiology and Biostatistics, \\ Perelman School of Medicine, University of Pennsylvania, Philadelphia, PA, USA \\ ${ }^{\mathrm{b}}$ Center for Clinical Epidemiology and Biostatistics, Department of Biostatistics, Epidemiology, and Informatics, \\ Perelman School of Medicine, University of Pennsylvania, Philadelphia, PA, USA \\ ${ }^{\mathrm{c}}$ Department of Neurology, Perelman School of Medicine, University of Pennsylvania, Philadelphia, PA, USA \\ ${ }^{\mathrm{d}}$ Department of Neurology Translational Center for Excellence for Neuroepidemiology and Neurological \\ Outcomes Research, University of Pennsylvania Perelman School of Medicine, Philadelphia, PA, USA \\ ${ }^{\mathrm{e}}$ Leonard Davis Institute of Health Economics, University of Pennsylvania Perelman School of Medicine, \\ Philadelphia, PA, USA \\ ${ }_{\mathrm{f}}^{\mathrm{f}}$ Raymond G. Perelman Center for Cellular \& Molecular Therapy, The Children's Hospital of Philadelphia, \\ Philadelphia, PA, USA \\ ${ }^{\mathrm{g}}$ Xavier University of Louisiana, New Orleans, LA, USA \\ ${ }^{\mathrm{h}}$ Penn Access Summer Scholars Program, University of Pennsylvania Perelman School of Medicine, Philadelphia, \\ $P A, U S A$
}

\begin{abstract}
. HDSA COE. COEs at the state level.

\footnotetext{
*Correspondence to: Thanh Phuong Pham Nguyen, PharmD,
} MBA, MSCE, 423 Guardian Drive, Blockley Hall 829, Philadelphia, PA 19104, USA. Tel.: +1 215573 4983; E-mail: phuongpn@ pennmedicine.upenn.edu.
\end{abstract}

Background: Huntington's Disease Society of America Centers of Excellence (HDSA COEs) are primary hubs for Huntington's disease (HD) research opportunities and accessing new treatments. Data on the extent to which HDSA COEs are accessible to individuals with HD, particularly those older or disabled, are lacking.

Objective: To describe persons with HD in the U.S. Medicare program and characterize this population by proximity to an

Methods: We conducted a cross-sectional study of Medicare beneficiaries ages $\geq 65$ with HD in 2017. We analyzed data on benefit entitlement, demographics, and comorbidities. QGis software and Google Maps Interface were employed to estimate the distance from each patient to the nearest HDSA COE, and the proportion of individuals residing within 100 miles of these

Results: Among 9,056 Medicare beneficiaries with HD, 54.5\% were female, $83.0 \%$ were white; $48.5 \%$ were $\geq 65$ years, but $64.9 \%$ originally qualified for Medicare due to disability. Common comorbidities were dementia (32.4\%) and depression $(35.9 \%)$, and these were more common in HD vs. non-HD patients. Overall, 5,144 (57.1\%) lived within 100 miles of a COE. Race/ethnicity, sex, age, and poverty markers were not associated with below-average proximity to HDSA COEs. 
The proportion of patients living within 100 miles of a center varied from $<10 \%$ (16 states) to $>90 \%$ ( 7 states). Most underserved states were in the Mountain and West Central divisions.

Conclusion: Older Medicare beneficiaries with HD are frequently disabled and have a distinct comorbidity profile. Geographical, rather than sociodemographic factors, define the HD population with limited access to HDSA COEs.

Keywords: Academic medical centers, health services accessibility, healthcare disparities, Huntington's disease, patientcentered care

\section{INTRODUCTION}

Huntington's disease (HD) is a fatal neurodegenerative genetic disorder caused by a cytosine-adenineguanine (CAG) repeat expansion on the huntingtin gene $[1,2]$. The prevalence of HD among U.S. Medicare beneficiaries was estimated to be around 13.1 per 100,000 persons in 2017 [3]. The CAG trinucleotide repeat leads to irregularities in protein function and ultimately to apoptosis of neurons in the brain $[1,4]$. Individuals with HD usually present with a combination of psychiatric, cognitive, and motor impairments, including depression, dementia and chorea, which progressively worsen over 10-20 years after the initial onset of symptoms until death $[1,5,6]$.

Although research efforts offer great promise, currently there is no cure for HD [7]. The gold standard for treatment is comprehensive multidisciplinary care to manage drug responsive symptoms, maximize function and maintain the highest possible quality of life until death [7-11], Huntington's Disease Society of America (HDSA) Centers of Excellence (COEs) are one source of onsite, same day multidisciplinary care, and are the entry point for nearly all HD research performed in the U.S. [11-14]. However, there are only 41 of these specialty centers across the U.S. in 2017 , and they are not equally distributed from a geospatial perspective [14]. Research from other areas of medicine suggests that increasing distance from appropriate care can negatively affect health care outcomes [15-18]. Moreover, specialty-center based clinical studies often systematically exclude individuals who have social or demographic risk factors such as older age, minority race, and poverty, and clinical factors such as dementia or advanced disease. Descriptive data on HD populations in the U.S. that are inclusive of all care sites are lacking $[2,19,20]$. To support efforts to provide equitable multidisciplinary care to all persons with $\mathrm{HD}$, and to provide epidemiological data on adults from understudied groups living with HD, we used Medicare data to 1) describe the population of persons living with HD in the U.S. who are receiving insurance from the public Medicare program, and 2) to identify and characterize the proportion of HD patients that are proximal to an HDSA COE.

\section{MATERIALS AND METHODS}

\section{Ethical compliance statement and data approval}

This study utilized Centers for Medicare and Medicaid Services Research Identifiable Files, made available to Dr. Willis under a data use agreement for epidemiology and health services research on neurodegenerative disease. The Institutional Review Board at the University of Pennsylvania granted approval for this study with waiver for individual consent. The authors confirm that patient consent was not required for this work and that we have read the Journal's position on issues involved in ethical publication and affirm that this work is consistent with those guidelines.

\section{Datasets}

This cross-sectional study utilized Research Identifiable Files from the Centers for Medicare and Medicaid Services from the year 2017. We utilized the Carrier File (which contains encounter level data on physician and other medical provider visits, laboratory testing), and the Medicare Beneficiary Summary Base File [MBSF] (which contain individual level data on race/ethnicity, age, sex, beneficiary mailing zip code, date of death and Medicaid eligibility), and the Chronic Condition Warehouse Files (which contain individual level data over 69 chronic health conditions identified using algorithms applied to all available Medicare data). The Medicare program supplies inpatient and outpatient health and prescription insurance to individuals ages 65 and above. Individuals under the age of 65 can qualify for Medicare by virtue of being designated as permanently disabled from a chronic medical condition 
or having end stage renal disease (ESRD) [21, 22]. Individuals with conditions like HD often qualify for Medicare before age 65 due to the severity of the disease, and HD is known to be present in older adults. We included all individuals enrolled in the Medicare program ages 18 and older, which includes individuals who received benefits initially due to older age and individuals who originally qualified due to disability.

\section{Study population}

We identified Medicare beneficiaries with HD as those with a health encounter with the International Classification of Diseases, Tenth Revision, Clinical Modification (ICD-10-CM) code of G10 in the year 2017. We extracted sociodemographic data for the resulting HD cohort from the MBSF base file. Age in years was measured as a continuous variable, and then categorized $(18-44,45-54,55-64,65-74,75-84$, $85+)$. Race/ethnicity was categorized as follows: White, Black, Unknown + Other, Hispanic, Asian, and Native North American. We extracted data on original reason for Medicare benefits: being age 65 and older, having a qualifying disability or ESRD. We identified those individuals also receiving Medicaid insurance, known as "dual eligibles." Medicaid insurance is provided to Medicare beneficiaries meeting low-income criteria, and dual eligibility is viewed as a marker of poverty in Medicare claims-based health services research [23]. We extracted Chronic Condition Warehouse File data on the diagnosis or treatment of common general medical, neurological, or disabling conditions [24]. Beneficiary mailing zip code is the most discrete geospatial variable available in Medicare Research Identifiable Files. Beneficiaries with a valid, identifiable zip code in the U.S., Puerto Rico, Guam, or the U.S. Virgin Islands were selected for the spatial analyses described below.

\section{Proximity to HDSA COEs}

Although high quality specialty care for HD is delivered at academic centers and specialty clinics across the country, Medicare claims data does not allow for automated identification of outpatient specialty centers, and there is no available source that maintains up-to-date data on all neurology centers providing a specific level of HD care in the U.S. Therefore, we focused on HDSA COEs, as these have met some external measures for specialty care and are primary centers for HD research. Addresses of all HDSA COEs in 2017 were retrieved from the
HDSA website [14]. The zip codes of the HD patients and HD centers were converted to their latitude and longitude coordinates. Latitude/longitude data were imported into QGis 3.10, a geographic information system application, and distance matrix vector analysis [25] was performed to identify the HDSA COE most proximal to each person with HD. Next, the Google Maps Distance Matrix Application Programming Interface (API) [26] was used to calculate the distance, in miles and kilometers, between the closest HDSA COE and each HD patient. For beneficiaries living on an island or island territory (e.g., Hawaii, Puerto Rico, U.S. Virgin Island), if there was no HDSA COE on the island, we calculated the distance from the island airport to the airport of the nearest HDSA COE. We categorized the distance to nearest COE as '100 miles or less', '101-250 miles', '251-500 miles', and '>500 miles', based on prior literature that posits a trip of 100 miles or less each way could be made safely in a single day [16, 17, 27-29].

\section{Statistical analyses}

Study variables were analyzed using descriptive statistics appropriate for the type and distribution of each variable. Our descriptive analyses of comorbid disease burden include a comparison to the general Medicare population, and therefore was restricted to individuals ages 65 and older. We created a map depicting the variation in proportions of individuals living within a 100-mile drive of a COE in each state. Statistical analyses were performed using IBM PASW v26 and illustrated figures were created using Python and Microsoft Excel. Statistical significance was set at $p<0.05$.

\section{RESULTS}

\section{Study sample sociodemographic characteristics}

Table 1 displays the demographic characteristics of our study sample. We identified 9,056 Medicare beneficiaries as having a diagnosis of HD in 2017. Just over half (51.4\%) of Medicare beneficiaries with HD were under the age of 65 , indicating they were currently qualified for Medicare benefits by virtue of disability. Moreover, among those ages 65 and above, 64.9\% first qualified for Medicare due to disability, not age. Women slightly outnumbered men $(54.5 \%$ versus $45.5 \%, p<0.01)$. In this U.S. sample, most HD patients were White (83.0\%), followed by Black (10.4\%), Hispanic (2.9\%), Other + Unknown (2.4\%), 
Table 1

Baseline characteristics of 9,056 Medicare beneficiaries with a claim for Huntington's disease care, 2017

\begin{tabular}{|c|c|c|c|}
\hline \multirow[t]{2}{*}{ Characteristic } & \multicolumn{2}{|c|}{$\begin{array}{c}\text { Medicare } \\
\text { Beneficiaries } \\
\text { with a claim } \\
\text { for HD in } \\
2017 \\
(n=9,056)\end{array}$} & \multirow[t]{2}{*}{$p^{\dagger}$} \\
\hline & $n$ & $\%$ & \\
\hline $\begin{array}{l}\text { Age in years (mean, SD; median, } \\
\text { IQR) }\end{array}$ & \multicolumn{2}{|c|}{$\begin{array}{l}62.1,14.1 \\
64.0,86\end{array}$} & NA \\
\hline Age groups & & & $<0.0001$ \\
\hline $18-44$ & 1,072 & 11.8 & \\
\hline $45-54$ & 1,562 & 17.2 & \\
\hline $55-64$ & 2,027 & 22.4 & \\
\hline $65-74$ & 2,672 & 29.5 & \\
\hline $75-84$ & 1,316 & 14.5 & \\
\hline $85+$ & 407 & 4.5 & \\
\hline Sex & & & $<0.0001$ \\
\hline Male & 4,125 & 45.5 & \\
\hline Female & 4,931 & 54.5 & \\
\hline Dual Eligible & & & $<0.0001$ \\
\hline Yes & 4,207 & 46.5 & \\
\hline No & 4,849 & 53.5 & \\
\hline Original reason for Entitlement & & & $<0.0001$ \\
\hline Age $>65$ & 3,077 & 34.0 & \\
\hline Disability & 5,875 & 64.9 & \\
\hline ESRD & 65 & 0.7 & \\
\hline ESRD and Disability & 39 & 0.4 & \\
\hline Race/Ethnicity & & & $<0.0001$ \\
\hline White & 7,513 & 83.0 & \\
\hline Black & 941 & 10.4 & \\
\hline Other + Unknown & 221 & 2.4 & \\
\hline Asian & 77 & 0.9 & \\
\hline Hispanic & 259 & 2.9 & \\
\hline Native North American & 45 & 0.5 & \\
\hline
\end{tabular}

${ }^{\dagger}$ Chi-square goodness-of-fit test-Bolded values indicate statistical significance. ESRD, end-stage renal disease; HD, Huntington's disease; IQR, interquartile range; NA, not applicable; $\mathrm{SD}$, standard deviation.

Asian (0.9\%), and Native North American (0.5\%).

\section{Comorbid disease patterns in geriatric HD}

In our HD sample limited to adults ages 65 and older, dementia was the most prevalent neurological comorbid condition, diagnosed in $32.4 \%$, followed by stroke/transient ischemic attack (16.4\%). Among psychiatric diagnoses, depression and anxiety were most common (35.9\% and $24.5 \%$, respectively). Chronic cardiovascular disorders- atrial fibrillation, ischemic heart disease, congestive heart failurewere also common (14.6\%-42.0\%); alcohol and opioid abuse, colorectal and lung cancers were relatively rare $(3.5 \%$ or less). HD patients rarely had noncognitive neurological diagnoses (such as epilepsy, migraine, traumatic brain injury).
Figure 1 shows the prevalence of common medical conditions in Medicare beneficiaries with and without an HD diagnosis. Prevalence ratios (PRs) estimated using these data were greatest for psychosis (PR 2.98, 95\% confidence interval [CI] 2.69-3.30), traumatic brain injury (PR 2.52, 95\% CI 2.01-3.17), dementia (PR 2.18, 95\% CI 2.07-2.29), and epilepsy (PR 2.04, 95\% CI 1.75-2.41). Cardiovascular conditions (congestive heart failure, ischemic heart disease, atrial fibrillation) were less prevalent in HD; the PRs ranged from 0.67 (95\% CI 0.62-0.73) for atrial fibrillation to 0.92 (95\% CI 0.87-0.97) for heart failure. Diabetes, chronic obstructive pulmonary disease (COPD), and chronic kidney disease were similarly common between the two groups.

\section{HDSA COE proximity}

In our sample, 9,003/9,056 (99.4\%) individuals had a zip code which met criterion for proximity analysis. Overall, $57.1 \%$ of Medicare beneficiaries with HD resided within one day's drive (0-100 miles) of an HDSA COE; $31.7 \%$ and $9.8 \%$ lived at 101-250 and 251-500 miles, respectively. As displayed in Table 2, proximity to a $\mathrm{COE}$ on this scale did not vary by age, sex, or dual eligible status. Compared to Whites and Blacks, a higher proportion of Asian (80.3\%) and Hispanic (63.7\%), Other/Unknown (70.2\%), but a lower proportion of Native North American $(31.1 \%)$ beneficiaries were in the most proximal group. As shown in Supplementary Table 1 and Fig. 2, individuals in the Mountain and Southwestern regions of the U.S., Alaska and Hawaii had the highest proportions of HD patients who lived greater than 100 miles from a COE. U.S. territories were not mapped.

\section{DISCUSSION}

In this study, we characterized the U.S. Medicare population of individuals with HD from sociodemographic and clinical perspectives, and then examined the proximity of individuals in this population sample to specialty care. Our primary findings are 1) a large number of older and disabled adults with HD can be identified in Medicare datasets, 2) geriatric HD patients have a high comorbidity burden, and 3) there are geographical disparities in access to HDSA COE care.

There is limited focus on the health, care, and outcomes of older adults with chronic neurological conditions, which we term neuroaging research, thus our finding of a large number of geriatric HD 


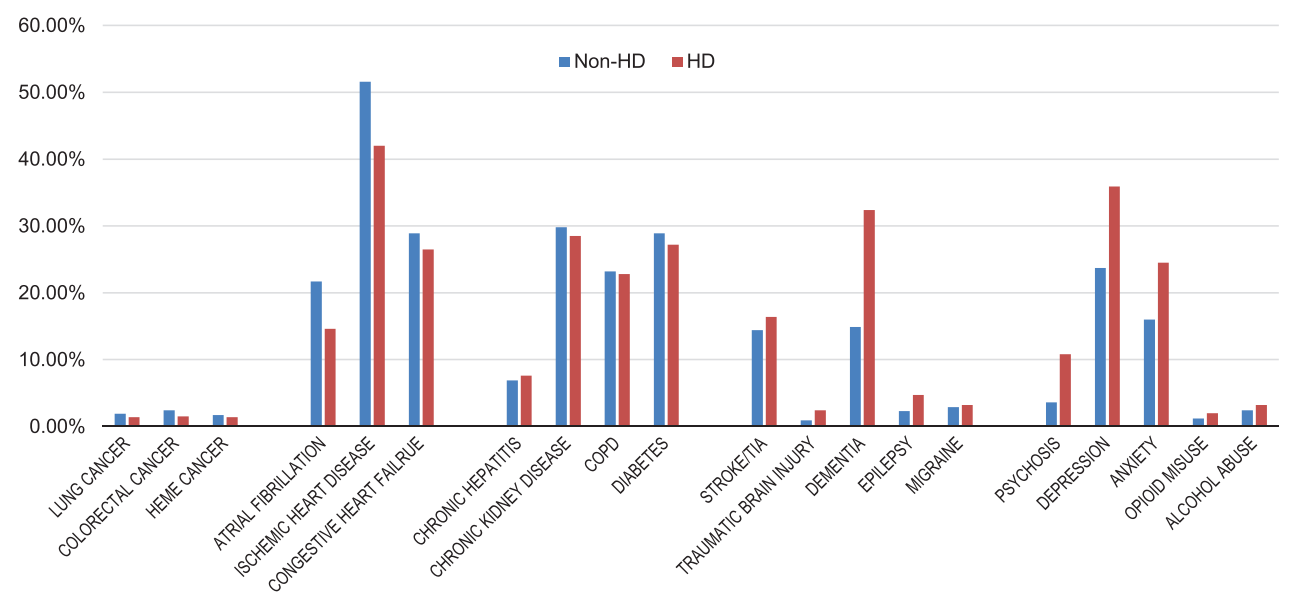

Fig. 1. Prevalence of Common Chronic Conditions Among U.S. Medicare Beneficiaries with and without Huntington's disease, 2017. NonHD, without Huntington's disease; HD, with Huntington's disease; COPD, chronic obstructive pulmonary disease; HEME, hematologic; TIA, transient ischemic attack.

Table 2

Proximity to Huntington's disease Centers of Excellence in Medicare beneficiaries with Huntington's disease, $2017(n=9,003)$

\begin{tabular}{|c|c|c|c|c|c|c|c|c|}
\hline \multirow[t]{2}{*}{ Characteristic } & \multicolumn{2}{|c|}{$\begin{array}{l}\text { less than } 100 \\
\text { miles }\end{array}$} & \multicolumn{2}{|c|}{$\begin{array}{c}101-250 \\
\text { miles }\end{array}$} & \multicolumn{2}{|c|}{$\begin{array}{c}251-500 \\
\text { miles }\end{array}$} & \multicolumn{2}{|c|}{$\begin{array}{c}\text { more than } 500 \\
\text { miles }\end{array}$} \\
\hline & $n$ & row\% & $n$ & row\% & $n$ & row\% & $n$ & row $\%$ \\
\hline \multicolumn{9}{|l|}{ Age group } \\
\hline $18-44$ & 596 & $56.0 \%$ & 327 & $30.7 \%$ & 129 & $12.1 \%$ & 13 & $1.2 \%$ \\
\hline $45-54$ & 867 & $55.7 \%$ & 522 & $33.6 \%$ & 149 & $9.6 \%$ & 17 & $1.1 \%$ \\
\hline $55-64$ & 1,138 & $56.5 \%$ & 645 & $32.0 \%$ & 205 & $10.2 \%$ & 27 & $1.3 \%$ \\
\hline $65-74$ & 1,546 & $58.2 \%$ & 816 & $30.7 \%$ & 258 & $9.7 \%$ & 35 & $1.3 \%$ \\
\hline $75-84$ & 770 & $58.8 \%$ & 399 & $30.5 \%$ & 118 & $9.0 \%$ & 22 & $1.7 \%$ \\
\hline $85+$ & 227 & $56.2 \%$ & 148 & $36.6 \%$ & 26 & $6.4 \%$ & $*$ & $<1 \%$ \\
\hline \multicolumn{9}{|l|}{ Sex } \\
\hline Male & 2,343 & $57.0 \%$ & 1,275 & $31.0 \%$ & 440 & $10.7 \%$ & 51 & $1.2 \%$ \\
\hline Female & 2,801 & $57.2 \%$ & 1,582 & $32.3 \%$ & 445 & $9.1 \%$ & 66 & $1.3 \%$ \\
\hline \multicolumn{9}{|l|}{ Primary payer } \\
\hline Medicare & 2,344 & $56.1 \%$ & 1,342 & $32.1 \%$ & 434 & $10.4 \%$ & 61 & $1.5 \%$ \\
\hline Medicare + Medicaid (dual eligible) & 2,800 & $58.1 \%$ & 1,515 & $31.4 \%$ & 451 & $9.4 \%$ & 56 & $1.2 \%$ \\
\hline \multicolumn{9}{|l|}{ Race/Ethnicity } \\
\hline White & 4,238 & $56.7 \%$ & 2,387 & $31.9 \%$ & 760 & $10.2 \%$ & 96 & $1.3 \%$ \\
\hline Black & 519 & $55.7 \%$ & 363 & $38.9 \%$ & 46 & $4.9 \%$ & $*$ & * \\
\hline Other + Unknown & 153 & $70.2 \%$ & 46 & $21.1 \%$ & 19 & $8.7 \%$ & $*$ & $<1 \%$ \\
\hline Asian & 57 & $80.3 \%$ & $*$ & $14.1 \%$ & $*$ & $5.6 \%$ & $*$ & $<1 \%$ \\
\hline Hispanic & 163 & $63.7 \%$ & 46 & $18.0 \%$ & 34 & $13.3 \%$ & 13 & $5.1 \%$ \\
\hline Native North American & 14 & $31.1 \%$ & $*$ & $11.1 \%$ & 22 & $48.9 \%$ & $*$ & $*$ \\
\hline
\end{tabular}

*Cells with number $<11$ are suppressed due to Centers for Medicare \& Medicaid Services policy.

patients may be surprising. Improved management of HD symptoms, preventive care, and comorbid disease care in general support greater survivorship for individuals with HD in any age group [30-36]. And, HD can manifest or become clinically evident at any age $[2,37]$. Although beyond the primary purpose of this study, the HD prevalence in our data is 8.3 per 100,000 Medicare beneficiaries ages 65 and older, which is within the accepted prevalence rate of 5-10 people per 100,000 persons [3, 4, 38, 39].
Taken together, these findings provide initial conceptual support for further health services research in geriatric HD populations using these data.

In this predominantly older sample, neuropsychiatric, cardiac, and metabolic disorders were the most commonly diagnosed comorbidities. Psychiatric disease and dementia are known manifestations of HD $[4,10,40-43]$, with prevalence rates from specialty clinic studies ranging from 5-69\% for dementia [44-47], 33-76\% for mood disorders [48-51]. 


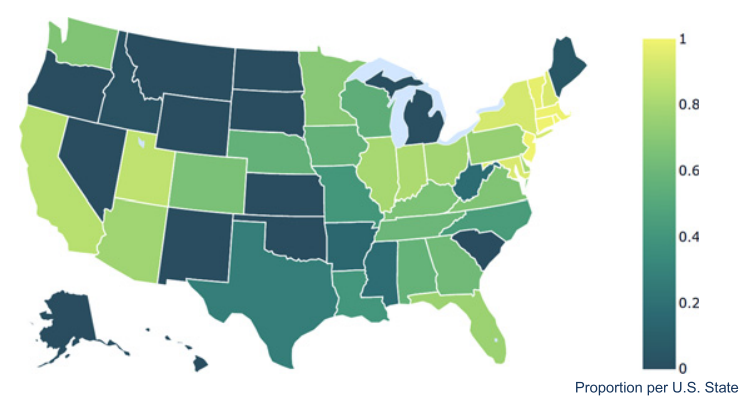

Fig. 2. Geographical Variations of Medicare Beneficiaries with Huntington's disease Living in Close Proximity ( $\leq 100$ miles) to a Huntington's disease Center of Excellence, 2017.

${ }^{\dagger}$ U.S. territories not shown on map.

Our finding of a high prevalence of cardiac and metabolic diseases may reflect aging, HD, or both. Cardiovascular events are disproportionately high in the HD population [52, 53], and neurocardiovascular pathology has been demonstrated in both pre-manifest and early-stage HD [54-57]. Geriatric HD patients may therefore be an ideal group for the study of the long-term effects of HD on the cardiovascular system, or, among patients with HD manifest at older ages, study of the interplay between HD and normal cardiovascular aging. Moreover, recent studies demonstrated a correlation between pre-existing hypertension [58] or diabetes [59] and an earlier age of symptom onset in HD patients. Although causality has not been shown, it is important to determine if hypertension and diabetes care correlate with longer survivorship. In both paradigms, the influence of other mediating factors such as antipsychotic induced metabolic disorder, anticholinergic or serotonergic drug related dysautonomia, access to and utilization of excellent primary preventative care, exercise programs, nutritional attainment and food security may emerge as important mediating factors.

Twenty-three states and three U.S. territories had a COE that was not easily reachable by at least half of their HD populations. This finding suggests that HDSA COE use among older HD patients is likely impacted by geographical disparities in access to such care, and that solutions to disparities in care will need to overcome geographical barriers as a first step. From a clinical perspective, HDSA COEs provide coordinated specialty care in neurology, psychiatry, psychology, palliative medicine, social work, physical, occupational and speech therapies, and genetic counseling. These clinical care specialists may be accessed locally, and some of the services listed are not needed frequently. Therefore, a negative clinical impact of the geographical disparities cannot be assumed. However, our finding of similar-to-higher proportions of historically underrepresented minorities or marginalized populations in proximity to HDSA COEs should be considered seriously, as it suggests that factors other than distance influence specialty center referrals and the demographic composition of HD trial participant samples. Efforts to better understand these patterns must not be limited to patient-impugning hypotheses such as language barriers and historical mistrust of the medical and scientific communities. Research focused on understanding how the current academic centerbased neurology specialty care models and processes (e.g., referral and recruitment practices) contribute to unequal use of services, even in uniformly insured populations, is more likely to lead to scalable, transportable, and effective solutions.

\section{Study strengths}

Strengths of this study include its ability to focus on the Medicare population, including geriatric HD, which is underrepresented in the literature. Our data identifies several areas for further inquiry: health service use and disparities, cardiovascular disease development and evolution, drug-disease interactions in the aging HD population. Our study also provides data that is useful for planning future sites for COEs, suggesting that telemedicine or video-based solutions may be an appropriate first choice for HD patients living in some areas of the U.S. [60].

\section{Study limitations}

The validity of HD codes in administrative health care databases is not yet known [61, 62], but genetic diseases, especially fatal ones, in general have good validity or acceptable accuracy [63-66]. Our cross-sectional design cannot account for individuals moving closer or away from COEs nor provide evidence that proximity to a COE associates with health care use, quality or outcomes; these relationships will be the focus of future longitudinal analyses. Although we chose previously published metrics for what is considered an acceptable driving distance for a single day, HD patients as a group may tolerate longer or shorter travel distances. Our use of Medicare claims allows a previously unpublished census of older adults with HD, at the expense of providing information on individuals with HD under the age of 65 who do not have Medicare coverage. Fur- 
thermore, Medicare claims do not include life history data, so we cannot make determinations about the duration of disease or time since diagnosis with this dataset. Finally, we examined the most recent year of data in our repository, 2017. Since then, more COEs have been established and the number of medical centers (COE designated or not) able to offer multidisciplinary HD care and research access may have changed in a manner that decreases, increases, or has no effect on the disparities we described here.

Progress in the care and management of chronic neurological conditions demands research at intersection of neurology and aging. In this study, we found that U.S. Medicare beneficiaries with HD are frequently disabled and have complex medical histories. There are also geographical barriers to HDSA COE access for some. Therefore, future research opportunities, particularly those which seek to understand HD in aging cohorts, may wish to consider including teleresearch recruitment options and focusing on improving telemedicine feasibility and outreach.

\section{ACKNOWLEDGMENTS}

This project was funded by the discretionary funds to Dr. Willis through the University of Pennsylvania Department of Neurology Translational Center for Excellence for Neuroepidemiology and Neurological Outcomes Research.

\section{CONFLICT OF INTEREST}

Dr. Pham Nguyen receives support from the National Institute of Health [Grant \#R01 NS099129] and Acadia, both unrelated to this work. Dr. Gonzalez-Alegre has received consulting fees unrelated to this work from Spark Therapeutics, Eisai Therapeutics and NeuExcell, and research funding from the National Institute of Health. Dr. Willis receives financial support from National Institutes of Health [Grant \#R01 NS099129], Acadia, and the University of Pennsylvania. Ms. Bravo declared no competing interests for this work.

\section{SUPPLEMENTARY MATERIAL}

The supplementary material is available in the electronic version of this article: https://dx.doi.org/ 10.3233/JHD-210489.

\section{REFERENCES}

[1] Walker FO. Huntington's disease. Lancet. 2007;369(9557): 218-28

[2] Bruzelius E, Scarpa J, Zhao Y, Basu S, Faghmous JH, Baum A. Huntington's disease in the United States: Variation by demographic and socioeconomic factors. Mov Disord. 2019;34(6):858-65.

[3] Exuzides A, Crowell V, Reddy SR, Chang E, Yohrling G. Epidemiology of Huntington's disease (HD) in the US Medicare population. Neurology. 2020;94(15 Supplement): 670.

[4] Ross CA, Tabrizi SJ. Huntington's disease: From molecular pathogenesis to clinical treatment. Lancet Neurol. 2011;10(1):83-98.

[5] MacDonald ME, Ambrose CM, Duyao MP, Myers RH, Lin $\mathrm{C}$, Srinidhi L, et al. A novel gene containing a trinucleotide repeat that is expanded and unstable on Huntington's disease chromosomes. Cell. 1993;72(6):971-83.

[6] Ma X, Gandhy R, Lu X-Y, Slowiejko D, Frank S. Clinical characteristics of late-onset Huntington's disease in North Americans from the Enroll-HD Study. Neurology. 2021; 96(15 Supplement):2247.

[7] Wyant KJ, Ridder AJ, Dayalu P. Huntington's diseaseupdate on treatments. Curr Neurol Neurosci Rep. 2017; 17(4):33.

[8] Boersma I, Miyasaki J, Kutner J, Kluger B. Palliative care and neurology: Time for a paradigm shift. Neurology. 2014; 83(6):561-7.

[9] McColgan P, Tabrizi SJ. Huntington's disease: A clinical review. Eur J Neurol. 2018;25(1):24-34.

[10] Bachoud-Levi AC, Ferreira J, Massart R, Youssov K, Rosser A, Busse M, et al. International guidelines for the treatment of Huntington's disease. Front Neurol. 2019;10:710.

[11] Carlozzi NE, Boileau NR, Chou KL, Ready RE, Cella D, McCormack MK, et al. HDQLIFE and neuro-QoL physical function measures: Responsiveness in persons with Huntington's disease. Mov Disord. 2020;35(2):326-36.

[12] Downing NR, Goodnight S, Chae S, Perlmutter JS, McCormack M, Hahn E, et al. Factors associated with end-of-life planning in Huntington disease. Am J Hosp Palliat Care. 2018;35(3):440-7.

[13] Paulsen JS, Long JD, Johnson HJ, Aylward EH, Ross CA, Williams JK, et al. Clinical and biomarker changes in premanifest Huntington disease show trial feasibility: A decade of the PREDICT-HD Study. Front Aging Neurosci. 2014; 6:78.

[14] Huntington's Disease Society of America Announces Forty-One 2017 HDSA Centers of Excellence New York, NY: Huntington's Disease Society of America; 2017 [updated 2017 Feb 8]. Available from: https://hdsa.org/ news/huntingtons-disease-society-of-america-announcesforty-one-2017-hdsa-centers-of-excellence/.

[15] Xu Y, Steckle S, Lui A, Dixon E, Ball CG, Sutherland FR, et al. Effect of proximity to specialty care on outcomes for biliary cancers: A population-based retrospective cohort study. CMAJ Open. 2019;7(1):E131-E9.

[16] Leira EC, Viscoli CM, Polgreen LA, Gorman M, Kernan WN, on behalf of the ITI. Distance from home to research center: A barrier to in-person visits but not treatment adherence in a stroke trial. Neuroepidemiology. 2018;50(3-4): 137-43.

[17] Sommerhalter KM, Insaf TZ, Akkaya-Hocagil T, McGarry CE, Farr SL, Downing KF, et al. Proximity to pediatric cardiac surgical care among adolescents with congenital heart 
defects in 11 New York counties. Birth Defects Res. 2017; 109(18):1494-503.

[18] Currow DC, Allingham S, Bird S, Yates P, Lewis J, Dawber $\mathrm{J}$, et al. Referral patterns and proximity to palliative care inpatient services by level of socio-economic disadvantage. A national study using spatial analysis. BMC Health Serv Res. 2012;12:424.

[19] Ohlmeier C, Saum KU, Galetzka W, Beier D, Gothe H. Epidemiology and health care utilization of patients suffering from Huntington's disease in Germany: Real world evidence based on German claims data. BMC Neurol. 2019;19(1): 318.

[20] Zarowitz BJ, O'Shea T, Nance M. Clinical, demographic, and pharmacologic features of nursing home residents with Huntington's disease. J Am Med Dir Assoc. 2014;15(6): 423-8.

[21] Who is eligible for Medicare? Washington, D.C.: U.S. Department of Health \& Human Services; 2021. Available from: https://www.hhs.gov/answers/medicare-andmedicaid/who-is-elibible-for-medicare/index.html

[22] Original Medicare (Part A and B) Eligibility and Enrollment. Baltimore, MD: U.S. Centers for Medicare \& Medicaid; [updated July 8, 2020]. Available from: https:// www.cms.gov/Medicare/Eligibility-and-Enrollment/Orig MedicarePartABEligEnrol.

[23] Clark WD, Hulbert MM. Research issues: Dually eligible Medicare and Medicaid beneficiaries, challenges and opportunities. Health Care Financ Rev. 1998;20(2):1-10.

[24] Chronic Conditions Data Warehouse. Condition Categories: Centers for Medicare \& Medicaid Services; 2019. Available from: https://www.ccwdata.org/web/guest/conditioncategories.

[25] QGIS 3.10 User Guide: QGIS Project; [updated 2020 December 9]. Available from: https://docs.qgis.org/3.10/ pdf/fi/QGIS-3.10-UserGuide-fi.pdf.

[26] Distance Matrix API: Google Web Services; 2021. Available from: https://developers-google-com.proxy.library. upenn.edu/maps/documentation/distance-matrix/intro.

[27] Polinski JM, Brookhart MA, Ayanian JZ, Katz JN, Kim SC, Lii J, et al. Relationships between driving distance, rheumatoid arthritis diagnosis, and disease-modifying antirheumatic drug receipt. Arthritis Care Res (Hoboken). 2014;66(11):1634-43.

[28] Longacre CF, Neprash HT, Shippee ND, Tuttle TM, Virnig BA. Evaluating travel distance to radiation facilities among rural and urban breast cancer patients in the Medicare population. J Rural Health. 2020;36(3):334-46.

[29] Banerjee R, Yi JC, Majhail NS, Jim HSL, Uberti J, Whalen $\mathrm{V}$, et al. Driving distance and patient-reported outcomes in hematopoietic cell transplantation survivors. Biol Blood Marrow Transplant. 2020;26(11):2132-8.

[30] Dash D, Mestre TA. Therapeutic update on Huntington's disease: Symptomatic treatments and emerging diseasemodifying therapies. Neurotherapeutics. 2020;17(4): 1645-59.

[31] Anderson KE, van Duijn E, Craufurd D, Drazinic C, Edmondson M, Goodman N, et al. Clinical management of neuropsychiatric symptoms of Huntington disease: Expertbased consensus guidelines on agitation, anxiety, apathy, psychosis and sleep disorders. J Huntingtons Dis. 2018; 7(3):355-66.

[32] Rodrigues FB, Abreu D, Damasio J, Goncalves N, CorreiaGuedes L, Coelho M, et al. Survival, mortality, causes and places of death in a European Huntington's disease prospective cohort. Mov Disord Clin Pract. 2017;4(5):737-42.
[33] McMurray CT. Huntington's disease: New hope for therapeutics. Trends Neurosci. 2001;24(11 Suppl):S32-8.

[34] Wright GEB, Black HF, Collins JA, Gall-Duncan T, Caron NS, Pearson CE, et al. Interrupting sequence variants and age of onset in Huntington's disease: Clinical implications and emerging therapies. Lancet Neurol. 2020;19(11): 930-9.

[35] Long JD, Mills JA, Leavitt BR, Durr A, Roos RA, Stout JC, et al. Survival end points for Huntington disease trials prior to a motor diagnosis. JAMA Neurol. 2017;74(11): 1352-60.

[36] Tabrizi SJ, Ghosh R, Leavitt BR. Huntingtin lowering strategies for disease modification in Huntington's disease. Neuron. 2019;101(5):801-19.

[37] Chaganti SS, McCusker EA, Loy CT. What do we know about late onset Huntington's disease? J Huntingtons Dis. 2017;6(2):95-103.

[38] Pringsheim T, Wiltshire K, Day L, Dykeman J, Steeves T, Jette N. The incidence and prevalence of Huntington's disease: A systematic review and meta-analysis. Mov Disord. 2012;27(9):1083-91.

[39] Meoni S, Macerollo A, Moro E. Sex differences in movement disorders. Nat Rev Neurol. 2020;16(2):84-96.

[40] Kay C, Hayden MR, Leavitt BR. Epidemiology of Huntington disease. Handb Clin Neurol. 2017;144:31-46.

[41] Cardoso F. Nonmotor symptoms in Huntington disease. Int Rev Neurobiol. 2017;134:1397-408.

[42] Snowden JS. The neuropsychology of Huntington's disease. Arch Clin Neuropsychol. 2017;32(7):876-87.

[43] Martinez-Horta S, Perez-Perez J, van Duijn E, FernandezBobadilla R, Carceller M, Pagonabarraga $J$, et al. Neuropsychiatric symptoms are very common in premanifest and early stage Huntington's disease. Parkinsonism Relat Disord. 2016;25:58-64.

[44] Dumas EM, van den Bogaard SJ, Middelkoop HA, Roos RA. A review of cognition in Huntington's disease. Front Biosci (Schol Ed). 2013;5:1-18.

[45] Julayanont P, McFarland NR, Heilman KM. Mild cognitive impairment and dementia in motor manifest Huntington's disease: Classification and prevalence. J Neurol Sci. 2020; 408:116523.

[46] Peavy GM, Jacobson MW, Goldstein JL, Hamilton JM, Kane A, Gamst AC, et al. Cognitive and functional decline in Huntington's disease: Dementia criteria revisited. Mov Disord. 2010;25(9):1163-9.

[47] Aldaz T, Nigro P, Sanchez-Gomez A, Painous C, Planellas L, Santacruz P, et al. Non-motor symptoms in Huntington's disease: A comparative study with Parkinson's disease. J Neurol. 2019;266(6):1340-50.

[48] Pla P, Orvoen S, Saudou F, David DJ, Humbert S. Mood disorders in Huntington's disease: From behavior to cellular and molecular mechanisms. Front Behav Neurosci. 2014;8: 135.

[49] van Duijn E, Kingma EM, van der Mast RC. Psychopathology in verified Huntington's disease gene carriers. J Neuropsychiatry Clin Neurosci. 2007;19(4):441-8.

[50] Naarding P, Kremer HP, Zitman FG. Huntington's disease: A review of the literature on prevalence and treatment of neuropsychiatric phenomena. Eur Psychiatry. 2001;16(8): 439-45.

[51] Craufurd D, Thompson JC, Snowden JS. Behavioral changes in Huntington disease. Neuropsychiatry Neuropsychol Behav Neurol. 2001;14(4):219-26.

[52] Abildtrup M, Shattock M. Cardiac dysautonomia in Huntington's disease. J Huntingtons Dis. 2013;2(3):251-61. 
[53] Zielonka D, Witkowski G, Puch EA, Lesniczak M, MazurMichalek I, Isalan M, et al. Prevalence of non-psychiatric comorbidities in pre-symptomatic and symptomatic Huntington's disease gene carriers in Poland. Front Med (Lausanne). 2020;7:79.

[54] 5Bellosta Diago E, Perez-Perez J, Santos Lasaosa S, Viloria Alebesque A, Martinez-Horta S, Kulisevsky J, et al. Neurocardiovascular pathology in pre-manifest and early-stage Huntington's disease. Eur J Neurol. 2018;25(7):956-62.

[55] Critchley BJ, Isalan M, Mielcarek M. Neuro-cardio mechanisms in Huntington's disease and other neurodegenerative disorders. Front Physiol. 2018;9:559.

[56] Andrich J, Schmitz T, Saft C, Postert T, Kraus P, Epplen JT, et al. Autonomic nervous system function in Huntington's disease. J Neurol Neurosurg Psychiatry. 2002;72(6): 726-31.

[57] Aziz NA, Anguelova GV, Marinus J, van Dijk JG, Roos RA. Autonomic symptoms in patients and pre-manifest mutation carriers of Huntington's disease. Eur J Neurol. 2010;17(8): 1068-74.

[58] Schultz JL, Harshman LA, Langbehn DR, Nopoulos PC. Hypertension is associated with an earlier age of onset of Huntington's disease. Mov Disord. 2020;35(9):1558-64

[59] Ogilvie AC, Gonzalez-Alegre P, Schultz JL. Diabetes mellitus is associated with an earlier age of onset of Huntington's disease. Mov Disord. 2021;36(4):1033-4.

[60] Lee SJ, Hale LM, Huitz E, Claassen DO, McDonell KE. Improving patient outreach by defining telehealth suitability in a tertiary Huntington's disease clinic. J Huntingtons Dis. 2021;10(4):479-84.
[61] St Germaine-Smith C, Metcalfe A, Pringsheim T, Roberts JI, Beck CA, Hemmelgarn BR, et al. Recommendations for optimal ICD codes to study neurologic conditions: A systematic review. Neurology. 2012;79(10):1049-55.

[62] Vicente E, Ruiz de Sabando A, Garcia F, Gaston I, Ardanaz E, Ramos-Arroyo MA. Validation of diagnostic codes and epidemiologic trends of Huntington disease: A populationbased study in Navarre, Spain. Orphanet J Rare Dis. 2021; 16(1):77.

[63] Grosse SD, Green NS, Reeves SL. Administrative data identify sickle cell disease: A critical review of approaches in U.S. health services research. Pediatr Blood Cancer. 2020; 67(12):e28703.

[64] Reeves S, Garcia E, Kleyn M, Housey M, Stottlemyer $\mathrm{R}$, Lyon-Callo S, et al. Identifying sickle cell disease cases using administrative claims. Acad Pediatr. 2014;14 (5 Suppl):S61-7.

[65] Lyons J, Desai V, Xu Y, Ridgeway G, Finkle W, Solari P, et al. Development and validation of an algorithm for identifying patients with hemophilia $\mathrm{A}$ in an administrative claims database. Value Health. 2018;21(9):1098-103.

[66] Smith MG, Royer J, Mann JR, McDermott S. Using administrative data to ascertain true cases of muscular dystrophy: Rare disease surveillance. JMIR Public Health Surveill. 2017;3(1):e2 